\title{
Investigation of oil-water flow regimes and pressure drops in mini-channels
}

\author{
Kevin K. Bultongez, Melanie M. Derby* \\ Department of Mechanical and Nuclear Engineering, Kansas State University, Manhattan, KS \\ *Corresponding author: derbym@ksu.edu \\ 3002 Rathbone Hall, Kansas State University, Manhattan, KS USA \\ Tel: 785-532-2606, Fax: 785-532-7057
}

\begin{abstract}
Oil-water flow regimes were studied in 2.1-mm and 3.7- $\mathrm{mm}$ borosilicate glass tubes; both tubes exhibit Eötvös numbers less than one and therefore surface tension forces may be more important in these mini-channels compared to larger diameter tubes. A closed-loop, adiabatic experimental apparatus was constructed and validated using water. This study focused on tap water and two mineral oils (i.e., Parol 70 and 100) with a density of $840 \mathrm{~kg} / \mathrm{m}^{3}$ but a factor of two difference in viscosity. Experiments included a wide range of oil superficial velocities (e.g., 0.84-6.84 m/s for $D=2.1 \mathrm{~mm}$ and $0.27-3.30 \mathrm{~m} / \mathrm{s}$ for $D=3.7 \mathrm{~mm}$ ) and water superficial velocities (e.g., $0.21-7.69 \mathrm{~m} / \mathrm{s}$ for $D=2.1 \mathrm{~mm}$ and $0.07-4.96 \mathrm{~m} / \mathrm{s}$ for $D=3.7 \mathrm{~mm}$ ). Stratified, annular, intermittent, and dispersed flow regimes were observed in both tubes, although the annular flow regime was more prevalent in the smaller tube. Pressure drops increased with decreasing tube diameter and were flow regime dependent. Flow maps were created for these mini-channels and equations adapted from Brauner and Maron (1999) were used to predict the flow regime transitions. The effects of viscosity were modest, although increased oil viscosity enhanced stability of oil-water flows.
\end{abstract}

Keywords: Mini-channel, oil-water, flow regime, flow regime map, Eötvös number, surface tension

\section{Highlights}

- Stratified, annular, intermittent, and dispersed flows were observed in mini-channels

- Annular flows were more prevalent in the smaller, 2.1-mm tube

- Flow regimes were mapped and flow transitions predicted for mini-channels

- Pressure drops were strong functions of flow rate, flow regime, and tube diameter 


\section{Introduction}

Advancements in technology and breakthroughs in oil processing have enabled the increased activity and growth of deepwater and ultra deepwater exploration (Addison, 2015; Chakhmakhchev and Rushworth, 2010; Dobson, 1998; EIA, 2003), with new discoveries frequently occurring at these depths (Chakhmakhchev and Rushworth, 2010). According to the U.S. Energy Information Administration, crude oil-derived fuel sources will continue to have an integral part in the country's present and future supply of energy (EIA, 2003). Crude oil contains undesirable impurities and corrosion agents such as chloride (i.e., salt). Even at low concentrations, salt forms scale and accelerates corrosion in piping equipment resulting in fouling and expensive cleanup (Pereira et al., 2015). Desalting, the removal of formation water from oil, is a vital process in crude oil recovery; however, the process becomes challenging at deepwater and ultra deepwater depths. Current desalting technology relies on a combination of gravitational and electrostatic forces to achieve desired oil-water separation. As crude oil densities approach that of water, in the case of heavy crude, gravitational forces alone become insufficient in separating salt water from oil. In the case of electrostatic forces, voltages in excess of 30,000 V are required (Cameron, 2010a, b, c), which is challenging to supply to the ocean floor. These challenges generate motivation for a different separation approach. The effects of surface tension forces in two-phase oil-water flows may yield a particular set of flow configurations (i.e., annular flows) which combined with membranes could be utilized in addition or as an alternative to current desalting methods. Understanding mini-scale oil-water flow patterns and pressure drops is an initial step towards future surface-tension-driven oil-water separation systems.

Despite the extensive research on gas-liquid flows, flow regime and pressure drop prediction models are not directly transferable to liquid-liquid flows. Density differences in oil-water flows are significantly lower than liquid-gas flows, which can differ by three orders of magnitude and viscosity differences in liquid-liquid flows span a wide range of multiple orders of magnitude (Hadžiabdić and Oliemans, 2007; Hall and Hewitt, 1993; Mandal et al., 2007). Modeling of singlephase liquids cannot be directly applied to liquid-liquid flows since multi-phase shear stresses can exceed single-phase wall shear stress by up to 400\% (Hadžiabdić and Oliemans, 2007). These differences are substantial, especially in the case of small diameter tubes where surface tension forces are dominant. 
Different types of oil-water flow regimes have been observed and documented in a variety of tube diameters: stratified, annular, intermittent, and dispersed flow are four of the main flows observed in horizontal tubes (Al-Wahaibi and Angeli, 2007, 2009; Angeli and Hewitt, 2000; Atmaca et al., 2008; Balakhrisna et al., 2010; Bannwart et al., 2004; Brauner and Maron, 1999; Brauner and Ullmann, 2002; Cobos et al., 2008; Coleman and Garimella, 2003; Das et al., 2005; Das et al., 2016; Edomwonyi-Otu and Angeli, 2015; Ismail et al., 2015; Joseph et al., 1997; Mandal et al., 2007; McKibben et al., 2000; Rodriguez and Oliemans, 2006; Salim et al., 2008; Sotgia et al., 2008; Taitel and Dukler, 1976; Tsaoulidis and Angeli, 2016; Tsaoulidis et al., 2013; Zhao et al., 2006). Stratified flows were most prevalent in horizontal tubes with diameters above $10 \mathrm{~mm}$ (AlWahaibi and Angeli, 2007; Atmaca et al., 2008; Bannwart et al., 2004; Das et al., 2005; Edomwonyi-Otu and Angeli, 2015; Hadžiabdić and Oliemans, 2007; Ismail et al., 2015; Joseph et al., 1997; Rodriguez and Oliemans, 2006; Taitel and Dukler, 1976); researchers noted that gravitational forces separated the denser water from the less dense oil, thereby forming distinct layers. Tube diameter had a strong impact on resulting flow regime. Two researcher groups (Ismail et al., 2015; Rodriguez and Oliemans, 2006) studied oil-water flow regimes in 50.8 and $82.8 \mathrm{~mm}$ horizontal pipes, respectively. Stratified and dispersed flows were the dominant flow regimes in these larger diameters, with few appearances of annular or intermittent flows. A review paper noted instabilites often occurred at stratified oil-water interface across several studies (Joseph et al., 1997). Many researchers observed interfacial waves in stratified flows (Al-Wahaibi and Angeli, 2007, 2009; Das et al., 2005; Ismail et al., 2015; Rodriguez and Oliemans, 2006), indicative of the stratified-wavy flow regime and a result of instabilities stemming from different oil and water velocities. These interfacial waves increased droplet entrainment (e.g., oil droplets in water or water droplets in oil) resulting in dispersed flow regimes (Angeli and Hewitt, 1999, 2000; Brauner and Ullmann, 2002; Cobos et al., 2008; McKibben et al., 2000; Rodriguez and Oliemans, 2006; Sotgia et al., 2008).

Intermittent and annular flows were more prevalent at smaller diameters. Intermittent plug or slug flow, a flow regime affected by interfacial forces in small channels, (Tsaoulidis and Angeli, 2016), was found in numerous microchannel applications, including fuel cells, thermal mangement systems, separation processes (e.g., solvent extraction), emulsification, and biochemistry analysis and syntesis. In these applications, desirable tube sizes range from $200 \mu \mathrm{m}$ to $6 \mathrm{~mm}$ (Das et al., 2010; Jovanović et al., 2011; Kashid et al., 2007; Kashid et al., 2011; Kiwi-Minsker et al., 2010; 
Tsaoulidis and Angeli, 2016; Tsaoulidis et al., 2013). In annular flow regimes, an annular water ring forms around an oil core which has been attributed to surface tension (Das et al., 2010; Das et al., 2016; Kashid and Kiwi-Minsker, 2011; Mandal et al., 2007; McKibben et al., 2000; Salim et al., 2008; Zhao et al., 2006). Charles et al. (1961) studied oil-water flows with similar densities in 25.4-mm tubes and noted intermittent flow regimes. Sotgia et al. (2008) observed stratified, annular, and dispersed flow regimes in 21-40 mm tubes. They noted a reduction in stratified flows, introduction of intermittent flows, and increased prevalence of annular flows in a 26-mm tube compared to a 40-mm tube. At even smaller diameters, the appearance of stratified flows dimished or disappeared in mini-channels for liquid-vapor flows (Agarwal et al., 2007; Coleman and Garimella, 2003; Jayawardena et al., 1997; Thome et al., 2003).

The Eötvös number is the ratio of gravitational forces to surface tension forces (Brauner and Maron, 1999), and it has been shown to impact flow regimes, particularly the transition to annular flow and the impacts of surface tension on flow regimes. Bannwart (2001) developed a theoretical core-annular flow model and applied it to experimental data from a 22.5-mm horizontal pipe. The Archimedes number did not influence flow regime transition in the best fit model, but the flow exhibited a strong dependence on the Eötvös number. Brauner and Moalem-Maron (1999) noted strong impacts of Eötvös number on flow regime. For larger Eötvös numbers with strong influences of gravity, stratified and dispersed flow regimes were observed at low and high flow rates, respectively and the researchers likened the flow regimes to gravity-driven, liquid-vapor flows. For surface-tension-dominated flows (i.e., low Eötvös numbers), annular flows were often more prevalent, similar to micro-gravity systems. Previous research studied horizontal oil-water flows in tubes with the following diameters: 248-498 $\mu$ m (Jovanović et al., 2011), $269 \mu \mathrm{m}$ (Kashid and Kiwi-Minsker, 2011), $400 \mu \mathrm{m}$ (Zhao et al., 2006), 667 and $793 \mu \mathrm{m}$ (Salim et al., 2008), 12 and 25 mm (Mandal et al., 2007), 14 mm (Edomwonyi-Otu and Angeli, 2015), 24.3 mm (Angeli and Hewitt, 2000), 28.4 mm (Bannwart et al., 2004), 38 mm (Al-Wahaibi and Angeli, 2007), 50.8 mm (Ismail et al., 2015), 53 mm (McKibben et al., 2000), 82.8 mm (Rodriguez and Oliemans, 2006).

The objectives of this work are to investigate the effects of mini-tube diameter and viscosity on horizontal oil-water flow regimes and pressure drop in regimes where surface tension forces may be important. Experiments were conducted in a 2.1-mm and 3.7-mm borosilicate glass mini- 
channel using tap water and two mineral oils, with a factor of two difference in viscosity, over a range of superficial velocities.

\section{Experimental apparatus}

\subsection{Closed-loop apparatus}

Water and mineral oil (i.e., Parol ${ }^{\circledR} 70$ or Parol ${ }^{\circledR}$ 100, Calumet) flows were studied in a closedloop experimental apparatus showed in Figure 1; properties of the test fluids are given in Table 1. The fluids are pumped separately from a storage tank via two external gear pumps (GC-M25.PF5S. E, Micropump) with 1HP 3450 RPM motors controlled by their respective variable frequency drives. The oil and water streams each enter a Coriolis flow meter (CMFS015M, Micro Motion) before being mixed together in a Y-junction. Pressure and temperature were measured at the inlet and outlet of the test section as shown in Figure 2 using pressure transducers (PX303-200G5V, Omega) and type T thermocouples (TMQSS-062U-6, Omega). After exiting the test section, the two-phase mixture was returned to the 30-gallon pressure vessel were the fluids separated via gravity. Tap water was selected instead of salt water for ease of use; the addition of salt to water increases surface tension and barely alters specific gravity (Thome et al., 2003).

\subsection{Test section}

Figure 1 shows the schematic diagram of the horizontal test section made of borosilicate glass tubes. Lengths labeled (A), (B), and (C) of the test section were different for the 2.1-mm and 3.7mm inner diameter tubes. The 3.7-mm test section had a total length of $1.29 \mathrm{~m}$; the developing region, length (A), of $0.735 \mathrm{~m}$ allowed the flow to fully develop before entering the 0.495-m fully developed region, length (B), where flow visualization data was recorded. The fully developed region comprised of components (1), (2), and (3) as shown in Figure 2. Component (1) with length (C) of 0.465-m was the glass segment of the fully developed region. Additional fittings were required to connect the glass capillary tube to the system; components (2) and (3) included a 9.5mm-i.d., 30-mm long tube adaptor and a 9.5-mm-i.d cross fitting, respectively. The 2.1-mm test section was a replica of the larger tube with shorter lengths. Lengths (A), (B), and (C) were 0.464m, 0.322-m and 0.292-m, respectively. Component (2) consisted of a 6.35-mm-i.d 30-mm long tube adaptor while component (3) was the same cross fitting used in the 3.7-mm tube. A 50-psi differential pressure transducer (Setra) with $\pm 0.25 \%$ FS accuracy was used to measure two-phase flow pressure drop across the fully developed region. Flow regime was visualized using a 
microscope (Leica S6 D) and high-speed camera (Fastec IL5). Green food coloring, only miscible in water, increased contrast and enhanced visualization of oil-water interfaces.

\section{Single-phase validation}

Single-phase tests were conducted using tap water to validate the experimental apparatus instrumentation. The total pressure drop in the test section was modeled to predict the pressure drop across the fully developed region of the test section. The model accounted for the minor losses in the diameter expansions between the glass tube and tube adapter (i.e., component (1-2)) and tube adapter to cross fitting (i.e., component (2-3)). The Darcy-Weisbach equation for pressure frictional loss along with the minor losses equation was used to calculate the pressure drop in the fully developed region of the test section, with the objective to confirm that minor losses across the measured length were negligible. Total pressure drop was modeled as

$$
\begin{gathered}
\mathrm{P}_{\text {total }}=\Sigma \Delta \mathrm{P}_{\text {major }}+\Sigma \Delta \mathrm{P}_{\text {minor }} \\
\Delta \mathrm{P}_{\text {major }}=\frac{8 \mathrm{fL} \dot{m}^{2}}{\rho \pi^{2} \mathrm{D}^{5}} \\
\Delta \mathrm{P}_{\text {minor }}=\frac{8 K \dot{\mathrm{m}}^{2}}{\rho \pi^{2} \mathrm{D}^{5}}
\end{gathered}
$$

where $\Delta P_{\text {total }}$ was the total pressure drop across all three components consisting of major and minor losses, $\Delta P_{\text {major }}$ and $\Delta P_{\text {minor }}$ were the sums of all major and minor losses, respectively. $L, D, \dot{m}$ and $\rho$, represent the length of the glass tube (component (1)), tube diameter, water mass flow rate, and water density, respectively, and $f$ and $K$ were Darcy's friction factor and minor loss coefficients, respectively. The minor head loss equation was used to calculate the pressure drop in the diameter expansions between components using minor loss coefficients of $K_{1}=0.6$ and $K_{2}=$ 0.23, for the diameter expansions between component (1-2) and (2-3), (Munson et al., 2006). The Colebrook-Haaland equation was used to calculate the friction factor for turbulent water flows in the 465-mm long glass and the tube adaptor, components (1) and (2) respectively,

$$
\begin{gathered}
\mathrm{f}=\frac{64}{\operatorname{Re}} \\
\frac{1}{\sqrt{\mathrm{f}}}=-1.8 \log _{10}\left[\left(\frac{\mathrm{e} / \mathrm{D}}{3.7}\right)^{1.11}+\frac{6.9}{\mathrm{Re}}\right] \quad \operatorname{Re}>4000
\end{gathered}
$$




$$
\operatorname{Re}=\frac{4 \dot{\mathrm{m}}}{\pi \mu \mathrm{D}}
$$

where $R e$ was Reynolds number, $\mu$ was viscosity and $e / D$ represented the relative tube roughness. The glass tube was modeled as a smooth pipe and an absolute roughness of $e=1.5 \mathrm{E}-5 \mathrm{~m}$ was used for the stainless steel tube adapter and component (2).

The water temperature of $22{ }^{\circ} \mathrm{C}$ and subsequent density of $998 \mathrm{~kg} / \mathrm{m}^{3}$ were maintained throughout the entire experiment. A 5-psi and 50-psi pressure transducer (Setra) with $\pm 0.25 \%$ FS accuracy were used in the 3.7-mm and 2.1-mm tubes, respectively, for single-phase validation tests. Figure 3 displays the results obtained from the pressure drop model compared to the measured data. The analytical pressure drop model showed excellent agreement with the experimental results with a mean percent error of under 5\% for both diameter tubes. Single-phase tests results indicate that the vast majority (98\%) of measured pressure drop was found in the glass portion of test section, Figure 2, component (1), resulting in negligible minor losses. Therefore, measured oil-water pressure drops will accurately represent two-phase pressure drops.

\section{Results and discussion}

\subsection{Governing parameters}

The governing flow parameters were evaluated according to definitions found in Sotgia et al. (2008). Superficial velocity is defined as the volumetric rate of a fluid flowing in a pipe divided by the pipe's cross-sectional area,

$$
\mathrm{j}_{\mathrm{w}}=\frac{\dot{\mathrm{m}}_{\mathrm{w}}}{\rho_{\mathrm{w}} \mathrm{A}} ; \quad \mathrm{j}_{\mathrm{o}}=\frac{\dot{\mathrm{m}}_{\mathrm{o}}}{\rho_{\mathrm{o}} \mathrm{A}}
$$

where $j_{w}, j_{o}, \dot{m}_{w}, \dot{m}_{o}, \rho_{w}, \rho_{o}$ and $A$ are the water and oil superficial velocities, mass flow rates, densities and cross-sectional area, respectively. The water input ratio, $\varepsilon$, was selected as a controlling variable to investigate the effects of different water flow rates on flow regimes and is defined as the ratio between the water superficial velocity and the mean velocity of the two phases along water mass flow rate,

$$
\varepsilon=\frac{\mathrm{j}_{\mathrm{w}}}{\mathrm{j}_{\mathrm{o}}+\mathrm{j}_{\mathrm{w}}}=\frac{\dot{\mathrm{m}}_{\mathrm{w}}}{\frac{\rho_{\mathrm{w}} \dot{\mathrm{m}}_{\mathrm{o}}}{\rho_{\mathrm{o}}}+\dot{\mathrm{m}}_{\mathrm{w}}} ; \dot{\mathrm{m}}_{\mathrm{w}}=\frac{\varepsilon \rho_{\mathrm{w}} \dot{\mathrm{m}}_{\mathrm{o}}}{(1-\varepsilon) \rho_{\mathrm{o}}}
$$


Experiments are conducted using a specified oil superficial velocity and water input ratio; Table 1 shows the tested ranges of water input ratio and their respective superficial velocities.

\subsection{Experimental procedure}

This studies uses the data collection process previously developed by the authors (Bultongez and Derby, 2016):

1. Select oil mass flow rate $\left(\dot{m}_{o 1}\right)$ and the range of water input ratios $(\varepsilon)$ to be tested.

2. Calculate water mass flow rates $\left(\dot{m}_{w}\right)$ from selected oil mass flowrate and water input ratio (Eq. 8)

3. Introduce water in the test section at the highest water input ratio $\left(\varepsilon_{\max }\right)$.

4. Introduce oil at chosen value $\left(\dot{m}_{o 1}\right)$.

5. Record pressure measurements and flow visualization at current $\left(\dot{m}_{o 1}, \dot{m}_{w 1}\right)$ pair once steady state has been reached.

6. Decreased water mass flow rate to match respective water input ratio and record data for new flow condition $\left(\dot{m}_{o 1}, \dot{m}_{w 2}\right)$ pair. Adjust oil mass flow rate $\left(\dot{m}_{o 1}\right)$ to keep fixed value throughout the range of water mass flow rates.

7. Repeat Step 5 until the lowest water input ratio is achieved $(\varepsilon \min )$.

8. Repeat entire experiment for a new fixed oil mass flow rate $\left(\dot{m}_{o 2}\right)$.

The experimental data recorded and provided in this study showed excellent repeatability. Measurements for single-phase validation tests were collected at steady state conditions and repeated multiple times in both tube diameters. For adiabatic oil-water tests, data repeatability was checked by selecting two sets of oil and water mass flow rates at random from each of the oil mass flowrates and repeating the experiments. Additional repeatability tests were conducted throughout the data collection process to ensure measurement consistency, particularly for flow regime transition ranges. Pressure drop and flow regime measurements were found to be repeatable across trials. Two-phase experimental measurements were also recorded once steady state was reached.

\subsection{Flow regime definitions}

The four dominant flow regimes observed in the study, shown in Table 3, are stratified, annular, intermittent, and dispersed. These flow regimes behaved differently under increased flow velocities, prompting an additional flow description. All flow regime videos and images shown in 
this study were obtained using a high-speed camera at 1500-2000 fps; videos were played back at 20 fps so flow phenomena could be perceived.

Stratified flow, $S$, (Table 3.1-2): a distinct, separated two-layer flow consisting of oil in full contact with the tube wall as the top layer and water in full contact with the tube wall as the bottom layer. Two different oil-water interfaces were observed in stratified flow due to flow conditions and are categorized as follows: stratified-smooth $\left(S_{\text {smooth }}\right)$, a smooth oil water interface, and stratified-wavy $\left(S_{\text {wavy }}\right)$, a wavy oil water interface.

Annular flow, A, (Table 3.3-6): a separated flow consisting of a continuous oil core phase surrounded by a water film annulus. Four different interfaces were observed in annular flow and are categorized based on the oil core behavior as follows: annular-stratified (Astratified), a stratified oil core with a thin or thick water film flowing on the bottom; annular-wavy $\left(A_{\text {wavy }}\right)$, a wavy oilwater interface; annular churn (A $\left.A_{\text {churn}}\right)$, a sheared and wavy oil core; and annular-dispersed (Adispersed), small water droplets dispersed in an oil core.

Intermittent flow, I, (Table 3.7-9): a cyclical flow pattern consisting of oil slugs or oil droplets in a continuous water phase. Three different interfaces were observed in the intermittent flow regime and are also categorized based on the oil phase behavior as follows: intermittent-slug $\left(I_{\text {slug }}\right)$, long or short smooth bullet shaped oil slugs; intermittent-churn $\left(I_{c h u r n}\right)$, sheared oil slugs in continuous water phase; intermittent-dispersed ( $I_{\text {dispersed }}$ ), sheared oil slugs or small droplets in a continuous water phase.

Dispersed flow, D, (Table 3.10-12): a mixed flow consisting of small oil droplets dispersed in a continuous water phase. Two different types of flow regimes were observed in dispersed flow and are categorized as follows: dispersed-churn ( $\left.D_{\text {churn }}\right)$, small sheared oil slugs and oil droplets distributed in a continuous water phase; dispersed-emulsion ( $\left.D_{\text {emulsion}}\right)$, small fine droplets in a continuous water phase or vice versa after phase change.

\subsection{Flow regime maps}


Figure 4 compares flow regimes observed in the 2.1-mm and 3.7-mm tubes for Parol 70 and Parol 100. The four dominant flow regimes, stratified, annular, intermittent, and dispersed flow, were observed in both tubes. All oil flows remained in the laminar region, $R e<2300$, while water transitioned from laminar to turbulent as superficial water velocities increased (Table 4). The stratified flow regimes occupies the low range of superficial velocity and water input ratio, $\varepsilon<0.3$. The observed stratified flows begins with a smooth interface, $S_{\text {smooth. }}$ The stratified flow regime interface becomes wavy, $S_{\text {wavy }}$, before transitions in two ways: stratified to intermittent or stratified to annular. The transition from stratified to intermittent flow occurs as water input ratio is elevated; populating the range of low oil superficial velocity and average-to-high water input ratio, $0.3<\varepsilon$ $<0.8$. The flow progresses from $I_{\text {slug }}$ at the lower range of water input ratio to $I_{\text {churn }}$ as water input ratio increases, and finally becomes Idispersed at high water input ratios. The intermittent flow regime transitions to dispersed flow at the highest recorded water input ratio and average superficial velocities. The transition from stratified to annular flow occurs as oil velocity increases at relatively low water input ratios. Annular flow is observed at water input ratios of $0.2<\varepsilon<0.6$ with oil superficial velocities of $1.5<j_{o}<6.75 \mathrm{~m} / \mathrm{s}$ in the $2.1-\mathrm{mm}$ tube and at water input ratios of $0.2<\varepsilon<0.5$ with oil superficial velocities of $1.0<j_{o}<4.5 \mathrm{~m} / \mathrm{s}$ in the $3.7-\mathrm{mm}$ tube. Similar to stratified flow, it was observed that annular flow transitions from annular to intermittent or annular to dispersed flow. The transition from annular to intermittent occurs as the continuous oil core breaks up as water velocity increases, generating intermittent-slug, churn, or dispersed flow in part due to the coupled oil velocity. Typically, the annular-to-dispersed flow transition was observed at high oil velocity with relatively low water input ratio and average oil velocity with high water input ratio. As shown in Figure 4, the dispersed flow regime occupies the high oil and water superficial velocity range and oil and water droplets are well mixed.

\subsection{Effects of diameter on flow regime}

Tube diameter had a significant effect on flow regime, which in turn showed a considerable influence on pressure drop. Oil-water flows with clear interfacial boundaries spanned a greater range in the smaller tube. This trend resembles microgravity gas-liquid systems at smaller Eötvös numbers, (Brauner and Maron, 1999). Though the majority of the data collected for the 2.1-mm tube were at higher superficial velocities than the 3.7-mm tube, as shown in Table 1, stratified flow appeared in all test cases and was mainly observed at low fluid velocities (e.g., $j_{o}<0.85 \mathrm{~m} / \mathrm{s}$ and $j_{w}<0.57 \mathrm{~m} / \mathrm{s}$ ) for both tubes. The presence of stratified flow at these test conditions suggests that 
gravitational forces may influence flow regimes in mini-channels. However, within the intermittent and dispersed regimes, oil-water stratification was minor as the oil core is nearly concentric in $I_{\text {slug, }} I_{\text {churn, }}$ Dannular, and Dchurn flow regimes (Table 3). Annular flow was more prominent in the smaller tube and sustained for higher flow conditions compared to the larger tube, whereas the intermittent flow regime was favored in the 3.7-mm tube and mainly consisted of $I_{\text {slug, }}$ with occasional stratification at the lower flow conditions. A sharper transition from intermittent to dispersed flow was observed in the larger tube. As shown in Figure 4a and b, $I_{\text {churn }}$ and $I_{\text {dispersed }}$ flow patterns, which mark the intermittent-to-dispersed flow transition, occurred at higher oil and water superficial velocities in the 2.1-mm tube compared to the larger tube. Intermittent slug formation can be affected by interfacial and shear forces that dominate given particular flow conditions (Tsaoulidis and Angeli, 2016). This progression maintained as dispersed flow was delayed in the 2.1-mm tube compared to the 3.7-mm tube as shown in Figure 5b and d, where dispersion occurred at total oil and water superficial velocity of about $3.5 \mathrm{~m} / \mathrm{s}$ in the larger tube compared to $8 \mathrm{~m} / \mathrm{s}$ in the smaller tube.

\subsection{Effect of viscosity on flow regime}

Mineral oils Parol 70 (P70) and Parol 100 (P100) were investigated in this study. As shown in Table 2, the oils have nearly identical fluid densities and differ in viscosity by a factor of two, with P100 being more viscous. As discussed in the literature (Al-Wahaibi and Angeli, 2007; Bannwart et al., 2004; Brauner and Maron, 1999; Brauner and Ullmann, 2002; Charles et al., 1961), the more viscous oil did exhibit an overall greater flow stability in comparison to the less viscous oil. However, despite the viscosity difference, the changes in flow regime pattern due to oil viscosity were fairly small. Nearly all flow regimes observed for P70-water flows were also observed for P100-water; the $S_{\text {wavy }}$ flow regime was an exception as it was recorded in P70 with the 3.7-mm tube (Figure 4c) and was not present for the three other test conditions. When looking at the 3.7mm tube, stratified flow was more dominant with P70 oil while the intermittent flow regime was dominant in P100. The annular and dispersed flow regimes were fairly similar in both oils, with P70 showing a slightly larger range in its less stable annular flow regime $\left(A_{\text {churn }}, A_{\text {dispersed }}\right)$. The flow regime and transition behaved a bit differently in the 2.1-mm tube. Stratified, annular, and intermittent flow patterns all had slightly larger ranges in P100 while dispersed flow dominated in 
P70. One possible explanation is the tendency of the less viscous fluid to mix, thereby accelerating droplet formation and entrainment, promoting the transition to dispersed flow regime patterns.

\subsection{Oil-water pressure drops}

Pressure drops were observed to be a strong function of fluid velocity and flow regime. Pressure drop measurements along with respective uncertainties are shown in Figure 5. Overall, at constant oil superficial velocity, pressure drop generally increased with increasing water input ratio. On a multiple occasions, within each constant oil velocity set, pressure drop showed significant changes as flow transitioned from one flow regime to the other. This can be seen in the majority of oil superficial velocities in Figure 5a,b,c and d, at $j_{o}=6.82 \mathrm{~m} / \mathrm{s}, 0.84 \mathrm{~m} / \mathrm{s}, 0.55 \mathrm{~m} / \mathrm{s}$, and $3.30 \mathrm{~m} / \mathrm{s}$,

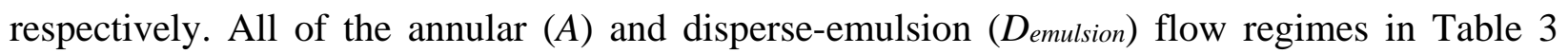
showed a dramatic change in measured pressure drop during flow transitions. At any given test condition, pressure drop measurements were the lowest in the annular flow regime. The decrease in pressure drop for annular flows is a desirable phenomenon as it directly relates to a smaller pumping power for unity oil mass (Bannwart et al., 2004). The opposite trend occurred at the transition to the disperse-emulsion flow regime; pressure drop sharply increased as a result of this flow transition. The difference in pressure drop between the two tube diameters mostly seem to correlate with their differences in flow regime; pressure drop in the 2.1-mm tube were higher than the 3.7-mm tube, however changes in pressure drop due to flow regime transition were similar at comparable superficial velocities.

Overall, the viscosity difference between the two oils did not show a major effect on pressure drop, except on few occasions. Shown in Figure $5 a$ and b, at approximately the same oil superficial velocity (i.e., $j_{0}=6.82 \mathrm{~m} / \mathrm{s}$ ) and similar water input ratios, less viscous P70 demonstrates elevated pressure drops compared to P100. Furthermore, P70 shows a momentary spike in pressure drop at the mentioned oil velocity and water input ratio of $\varepsilon=0.3$, Figure 6 a. This spike in pressure was measured multiple times and was shown to be a consistent and repeatable data point. According previous studies (Brauner and Ullmann, 2002), this phenomenon may be attributed to water-to-oil phase inversion, where a drastic increase in pressure drop is a natural outcome. Phase inversion, the spontaneous interchange between the continuous and dispersed phase, typically occurs in the dispersed flow regime at specific test conditions. Flow regime was the ultimate factor in comparison of pressure drops in both oils. However, when looking at similar flow conditions that 
yielded in comparable flow regimes, pressure drops were consistently a little higher in P70. In all comparable cases investigated, flow regimes in less viscous oil, P70, were slightly more unstable or displayed more disturbances to the flow, than its more viscous counterpart.

Pressure drop models for annular (Brauner, 1991) and dispersed flows (Brauner, 2003) are compared to experimental data and shown in Figure 6. Both models were derived for larger diameter tubes (e.g., 25-mm). The annular flow model by Brauner (1991) uses a two-fluid model approach, eliminating the pressure gradient in both core and wall region by combining the wall and interfacial shear stresses and presenting results in terms of the Lockhart-Martinelli parameter based on superficial velocities. The Brauner (2003) annular model predictions shown in Figure 6 are based on the lower viscous oil, P70. The model matches the experimental data well for the lower velocity range for both diameter tubes. However, for the 2.1-mm tube, some deviation from the pressure drop model occurs at higher flow rates. This could be due in part to the model's assumption of no water-in-oil or oil-in-water entrainment in all annular flow conditions, while experimental data show annular-dispersed flow at higher flow rates. The pressure gradient in the dispersed flow model is determined as the frictional pressure of the continuous phase using mixture density, $\rho_{o w}=\rho_{w} \varepsilon+\rho_{o}(1-\varepsilon)$, and mixture velocity as the total superficial velocity of both phases, $j_{o w}=j_{w}+j_{o}$. The friction factor is calculated using the Blasius correlation for turbulent flow in smooth tubes using mixture Reynolds number. The model captured the experimental trends although showed some limitations for predicting pressure drops at higher superficial velocities.

\subsection{Transition lines}

Using liquid-liquid flow experimental data (Guzhov et al., 1973; Mewes et al., 1997), Brauner and Maron (1999) generated flow transition equations, Table 5, to predict oil-water flow regimes for larger tubes (e.g., $60<E o<170$ ). Figure 7 compares Brauner and Maron's model predictions with the data collected in the much smaller diameter tubes investigated in this study (e.g., Eo<1). All boundaries shown in Figure 7 were generated using superficial velocities and test conditions from this study. In the model, boundary 2o shows the transition between stratified-smooth to stratifieddispersed assuming even oil and water layers and a laminar oil layer at all conditions. While this study did not observe the stratified-dispersed flow, boundary 2o presents a fairly accurate prediction for stratified-smooth to the annular flow regime transition, in the 2.1-mm tube, and stratified to intermittent flow transition in the 3.7-mm tube. From the model, boundary 4 represents 
the transition to dispersed flow, oil-in-water emulsion. The original line did not agree with the collected mini-channel data. An attempt to account for the difference in test conditions was done by increasing a correction factor in the boundary 4 equation by an order of magnitude, thus generating boundary 4', which seem to form a better boundary prediction for the larger 3.7-mm tube marking the transition from intermittent to disperse at lower oil superficial velocities. Transition to water in oil dispersed flow, boundary 5, occurred at higher superficial oil and water velocities in the model. A similar correction was carried out to generate boundary 5', however, water in oil dispersed flow regime was not observed in this study. Boundary 6 and 7 were not modified. The transition to dispersed phase inversion, Boundary 6, occurred at lower flow velocities in the model relative to the current study. Boundary 7, the transition from annular to intermittent flow, agreed fairly well with the collected data at the lower end of the oil and water superficial velocities. The boundary lines showed to be a good prediction to the transition of $A_{\text {wavy }}$ to $I_{\text {slug }}$ and $I_{\text {churn }}$ flow regimes.

\section{Conclusions}

A closed loop experimental apparatus with borosilicate-glass test sections was constructed and adiabatic oil-water flows were studied and visualized in two mini-channel tubes, $2.1 \mathrm{~mm}$ and 3.7 mm for a range of flow velocities. The two mineral oils investigated, Parol 70 and Parol 100, were of identical densities with a factor of two difference in viscosity. Single-phase validation, flow regime identification, and two-phase pressure drop measurements were presented for a range of experimental conditions. The effects of tube diameter and oil viscosity on two-phase flow regimes and flow transitions were reported. The main conclusions of this study are as follows:

- Single phase studies validated the major and minor losses in the experimental test section. Tap water was the working fluid and the model showed excellent agreement with the experimental results, having a mean percent error of under $5 \%$ for both diameter tubes.

- A two-phase flow map was constructed. Four flow regimes (i.e., stratified, annular, intermittent, and dispersed flow) were observed and recorded for both tubes. A description for each of the two-phase flow regimes was provided along with their respective modifications under different flow conditions. Transitions between flow regimes were 
discussed. A transition line model by Brauner and Maron (1999) for larger tubes was used and compared relatively well with the study's experimental results.

- Tube diameter had significant effects on flow regime. Oil-water flows with clear interfacial boundaries spanned a greater range in the smaller diameter tube even at higher fluid velocities. Stratification was diminished as inertial forces increased and annular flow was more prominent in the 2.1-mm tube. All flows except for stratified and dispersed-emulsion flow showed a water film in contact with the wall.

- The difference in viscosity in the two oil tested did not have a significant effect on flow regime. However, the more viscous oil (P100) showed greater overall flow stability opposed to P70.

- Pressure drops were observed to be a strong function of fluid velocity and flow regime. Flow regime transitions attributed to a significant change in pressure drop. Annular flow regime showed dramatic pressure decrease while dispersed-emulsion flow recorded the higher pressure drops.

\section{Acknowledgments}

The authors gratefully acknowledge support the financial support by OneSubea, Jacob Dunshee in constructing the experimental apparatus, and Glen Riley in collecting the expererimental data.

\section{NOMENCLATURE}

A area, $\mathrm{m}^{2}$

$\beta$ downward inclination to the horizontal

$D$ diameter, $\mathrm{m}$

$e$ tube roughness, $\mathrm{m}$

$f \quad$ Darcy friction factor

$g$ gravitational acceleration, $\mathrm{m} / \mathrm{s}^{2}$

$j$ superficial velocity, $\mathrm{m} / \mathrm{s}$

$K$ loss coefficient

$L$ length, $\mathrm{m}$

$\dot{m}$ mass flow rate, $\mathrm{kg} / \mathrm{s}$

Re Reynolds number

$P$ pressure, $\mathrm{Pa}$

$V$ velocity, $\mathrm{m} / \mathrm{s}$ 


$$
\begin{array}{ll}
\varepsilon & \text { water input ratio } \\
\mu & \text { viscosity, } \mathrm{mPa} \text { s } \\
\rho & \text { density, } \mathrm{kg} / \mathrm{m}^{3}
\end{array}
$$

Subscripts:

1 upper layer, or phase 1

2 lower layer, or phase 2

o oil

w water

\section{References}

Addison, V., 2015. Forecast: Deepwater Spend Will Reach \$210 Billion By 2019, E\&P Magazine, http://www.epmag.com/forecast-deepwater-spend-will-reach-210-billion-2019-789801.

Agarwal, A., Bandhauer, T.M., Garimella, S., 2007. Heat transfer model for condensation in noncircular microchannels, ASME 2007 5th International Conference on Nanochannels, Microchannels, and Minichannels. American Society of Mechanical Engineers, pp. 117-126.

Al-Wahaibi, T., Angeli, P., 2007. Transition between stratified and non-stratified horizontal oilwater flows. Part I: Stability analysis. Chemical Engineering Science 62, 2915-2928.

Al-Wahaibi, T., Angeli, P., 2009. Predictive model of the entrained fraction in horizontal oil-water flows. Chemical Engineering Science 64, 2817-2825.

Angeli, P., Hewitt, G., 1999. Pressure gradient in horizontal liquid-liquid flows. International journal of multiphase flow 24, 1183-1203.

Angeli, P., Hewitt, G., 2000. Flow structure in horizontal oil-water flow. International journal of multiphase flow 26, 1117-1140.

Atmaca, S., Sarica, C., Zhang, H.-Q., Al-Sarkhi, A., 2008. Characterization of oil water flows in inclined pipes, SPE Annual Technical Conference and Exhibition. Society of Petroleum Engineers, 1273-1286.

Balakhrisna, T., Ghosh, S., Das, G., Das, P., 2010. Oil-water flows through sudden contraction and expansion in a horizontal pipe-Phase distribution and pressure drop. International Journal of Multiphase Flow 36, 13-24.

Bannwart, A.C., Rodriguez, O.M., de Carvalho, C.H., Wang, I.S., Vara, R.M., 2004. Flow patterns in heavy crude oil-water flow. Journal of energy resources technology 126, 184-189.

Brauner, N., 1991. Two-phase liquid-liquid annular flow. International journal of multiphase flow 17, 59-76.

Brauner, N., 2003. Liquid-liquid two-phase flow systems, Modelling and Experimentation in TwoPhase Flow. Springer, pp. 221-279.

Brauner, N., Maron, D.M., 1999. 'Classification of Liquid-Liquid Two-Phase Flow Systems and The Prediction of Flow Pattern Maps, 2nd International Symposium on Two-Phase Flow Modeling and Experimentation-ISTP, pp. 747-754.

Brauner, N., Ullmann, A., 2002. Modeling of phase inversion phenomenon in two-phase pipe flows. International Journal of Multiphase Flow 28, 1177-1204.

Bultongez, K.K., Derby, M.M., 2016. Oil-Water Flow Visualization and Flow Regimes in a 3.7 mm Mini-Channel, ASME 2016 14th International Conference on Nanochannels, Microchannels, and Minichannels collocated with the ASME 2016 Heat Transfer Summer Conference and the 
ASME 2016 Fluids Engineering Division Summer Meeting. American Society of Mechanical Engineers, pp. V001T003A006-V001T003A006.

Cameron, 2010a. Cameron Site Map Products: BILECTRIC ${ }^{\circledR}$ High Frequency (HF), September 2014, http://www.c-a-m.com/forms/SiteMap.aspx.

Cameron, 2010b. Cameron Site Map Resaurces: PETRECO ${ }^{\circledR}$ BILECTRIC ${ }^{\circledR}$ Dehydrators Desalters, September 2014, September 2014, http://www.c-a-m.com/forms/SiteMap.aspx.

Cameron, 2010c. Process Systems- NATCO Electro-Dynamic Desalter (EED), September 2014, http://www.c-a-m.com/Forms/Product.aspx?prodID=387f1a88-0236-4aed-b0ca-818d80fb9b95.

Chakhmakhchev, A., Rushworth, P., 2010. Global overview of offshore oil \& gas operations for 2005-2009. Offshore 70, 32-38.

Charles, M.E., Govier, G.t., Hodgson, G., 1961. The horizontal pipeline flow of equal density oilwater mixtures. the Canadian Journal of Chemical engineering 39, 27-36.

Cobos, S., Carvalho, M., Alvarado, V., 2008. Flow of Oil-Water Emulsion Through Constricted Capillary Tubes, The XV international congress on rheology: The Society of Rheology 80th Annual Meeting. AIP Publishing, pp. 997-999.

Coleman, J.W., Garimella, S., 2003. Two-phase flow regimes in round, square and rectangular tubes during condensation of refrigerant R134a. International Journal of Refrigeration 26, 117128.

Das, G., Chakrabarti, D., Ray, S., 2005. Pressure drop in liquid-liquid two phase horizontal flow: experiment and prediction. Chemical Engineering and Technology 28, 1003-1009.

Das, G., Ghosh, S., Das, P.K., 2010. Simulation of core annular downflow through CFD-A comprehensive study. Chemical Engineering and Processing: Process Intensification 49, 12221228.

Das, G., Kannan, A., Ray, S., 2016. Liquid-liquid flow patterns in reduced dimension based on energy minimization approach. AIChE Journal 62, 287-294.

Dobson, M.K., J.C. Chatto, 1998. Condensation in smooth horizontal tubes. Journal of Heat Transfer 120, 193-213.

Edomwonyi-Otu, L.C., Angeli, P., 2015. Pressure drop and holdup predictions in horizontal oilwater flows for curved and wavy interfaces. Chemical Engineering Research and Design 93, 5565.

EIA, U.S., 2003. Annual Energy Outlook 2014 Early Release Overview, September 2014, http://www.eia.gov/forecasts/aeo/er/pdf/0383er(2014).pdf.

Guzhov, A., Grishan, A., Medredev, V., Medredeva, O., 1973. Emulsion formation during the flow of two immiscible liquids in a pipe. Neft Khoz 8, 58-61.

Hadžiabdić, M., Oliemans, R., 2007. Parametric study of a model for determining the liquid flowrates from the pressure drop and water hold-up in oil-water flows. International Journal of Multiphase Flow 33, 1365-1394.

Hall, A., Hewitt, G., 1993. Application of two-fluid analysis to laminar stratified oil-water flows. International journal of multiphase flow 19, 711-717.

Hong, K., Song, T., 2007. Development of optical naphthalene sublimation method. International Journal of Heat and Mass Transfer 50, 3890-3898.

Ismail, A.S.I., Ismail, I., Zoveidavianpoor, M., Mohsin, R., Piroozian, A., Misnan, M.S., Sariman, M.Z., 2015. Experimental investigation of oil-water two-phase flow in horizontal pipes: Pressure losses, liquid holdup and flow patterns. Journal of Petroleum Science and Engineering 127, 409420. 
Jayawardena, S.S., Balakotaiah, V., Witte, L.C., 1997. Flow pattern transition maps for microgravity two-phase flows. AIChE Journal 43, 1637-1640.

Joseph, D.D., Bai, R., Chen, K., Renardy, Y.Y., 1997. Core-annular flows. Annual Review of Fluid Mechanics 29, 65-90.

Jovanović, J., Zhou, W., Rebrov, E.V., Nijhuis, T., Hessel, V., Schouten, J.C., 2011. Liquid-liquid slug flow: hydrodynamics and pressure drop. Chemical Engineering Science 66, 42-54.

Kashid, M., Harshe, Y., Agar, D.W., 2007. Liquid- liquid slug flow in a capillary: an alternative to suspended drop or film contactors. Industrial \& Engineering Chemistry Research 46, 84208430.

Kashid, M., Kiwi-Minsker, L., 2011. Quantitative prediction of flow patterns in liquid-liquid flow in micro-capillaries. Chemical Engineering and Processing: Process Intensification 50, 972-978.

Kashid, M., Renken, A., Kiwi-Minsker, L., 2011. Influence of flow regime on mass transfer in different types of microchannels. Industrial \& Engineering Chemistry Research 50, 6906-6914.

Kiwi-Minsker, L., Dessimoz, A.-L., Raspail, P., Berguerand, C., 2010. Quantitative criteria to define flow patterns in micro-capillaries. Chemical Engineering Journal 160, 882-890.

Mandal, T., Chakrabarti, D., Das, G., 2007. Oil water flow through different diameter pipes: similarities and differences. Chemical Engineering Research and Design 85, 1123-1128.

McKibben, M.J., Gillies, R.G., Shook, C.A., 2000. A laboratory investigation of horizontal well heavy oil—water flows. The Canadian Journal of Chemical Engineering 78, 743-751.

Mewes, D., Nadler, M., Tokarz, A., 1997. The effect of emulsification on the flow behaviour of two immiscible liquids in horizontal pipes, ICHMT Digital Library Online. Begel House Inc.

Munson, B.R., Young, D.F., Okiishi, T.H., 2006. Fundamentals of Fluid Mechanics, John Wiley \& Sons. Inc., USA.

Pereira, J., Velasquez, I., Blanco, R., Sanchez, M., Pernalete, C., Canelón, C., 2015. Crude Oil Desalting Process, "Advances in Petrochemicals." $1^{\text {st }}$ ed., 67-84.

Rodriguez, O., Oliemans, R., 2006. Experimental study on oil-water flow in horizontal and slightly inclined pipes. International Journal of Multiphase Flow 32, 323-343.

Salim, A., Fourar, M., Pironon, J., Sausse, J., 2008. Oil-water two-phase flow in microchannels: Flow patterns and pressure drop measurements. The Canadian Journal of Chemical Engineering 86, 978-988.

Sotgia, G., Tartarini, P., Stalio, E., 2008. Experimental analysis of flow regimes and pressure drop reduction in oil-water mixtures. International Journal of Multiphase Flow 34, 1161-1174.

Taitel, Y., Dukler, A., 1976. A model for predicting flow regime transitions in horizontal and near horizontal gas-liquid flow. AIChE Journal 22, 47-55.

Thome, J.R., El Hajal, J., Cavallini, A., 2003. Condensation in horizontal tubes, part 2: new heat transfer model based on flow regimes. International Journal of Heat and Mass Transfer 46, 33653387.

Tsaoulidis, D., Angeli, P., 2016. Effect of channel size on liquid-liquid plug flow in small channels. AIChE Journal 62, 315-324.

Tsaoulidis, D., Dore, V., Angeli, P., Plechkova, N.V., Seddon, K.R., 2013. Flow patterns and pressure drop of ionic liquid-water two-phase flows in microchannels. International Journal of Multiphase Flow 54, 1-10.

Zhao, Y., Chen, G., Yuan, Q., 2006. Liquid-liquid two-phase flow patterns in a rectangular microchannel. AIChE journal 52, 4052-4060. 


\section{List of Figures:}

Figure 1 Experimental oil-water closed loop apparatus

Figure 2 Experimental apparatus test section. A, B, and C represent the lengths of the developing region, fully developed region, and glass section of the fully developed region

Figure 3 Single-phase water pressured drop for a) $2.1 \mathrm{~mm}$ and b) $3.7 \mathrm{~mm}$ tube

Figure 4 Mini-channel oil and water flow regime maps based on superficial velocity for a) 2.1-mm and b) 3.7-mm for both oils Parol 70 and Parol 100

Figure 5 Pressure drop per unit length for a) $D=2.1 \mathrm{~mm}$ and P70, b) $D=2.1 \mathrm{~mm}$ and P100, c) $D=3.7$ $\mathrm{mm}$ and P70, and d) $D=3.7 \mathrm{~mm}$ and $P 100$

Figure 6 Experimental and predicted pressure drop comparison with the Brauner (1991) model for annular flows and Brauner (2003) model for dispersed flows

Figure 7 Flow regime map transition lines for a) $D=2.1 \mathrm{~mm}$ and $P 70, b) D=2.1 \mathrm{~mm}$ and $P 100$, c) $D=3.7$ $\mathrm{mm}$ and P70, d) $D=3.7 \mathrm{~mm}$ and $\mathbf{P 1 0 0}$ 


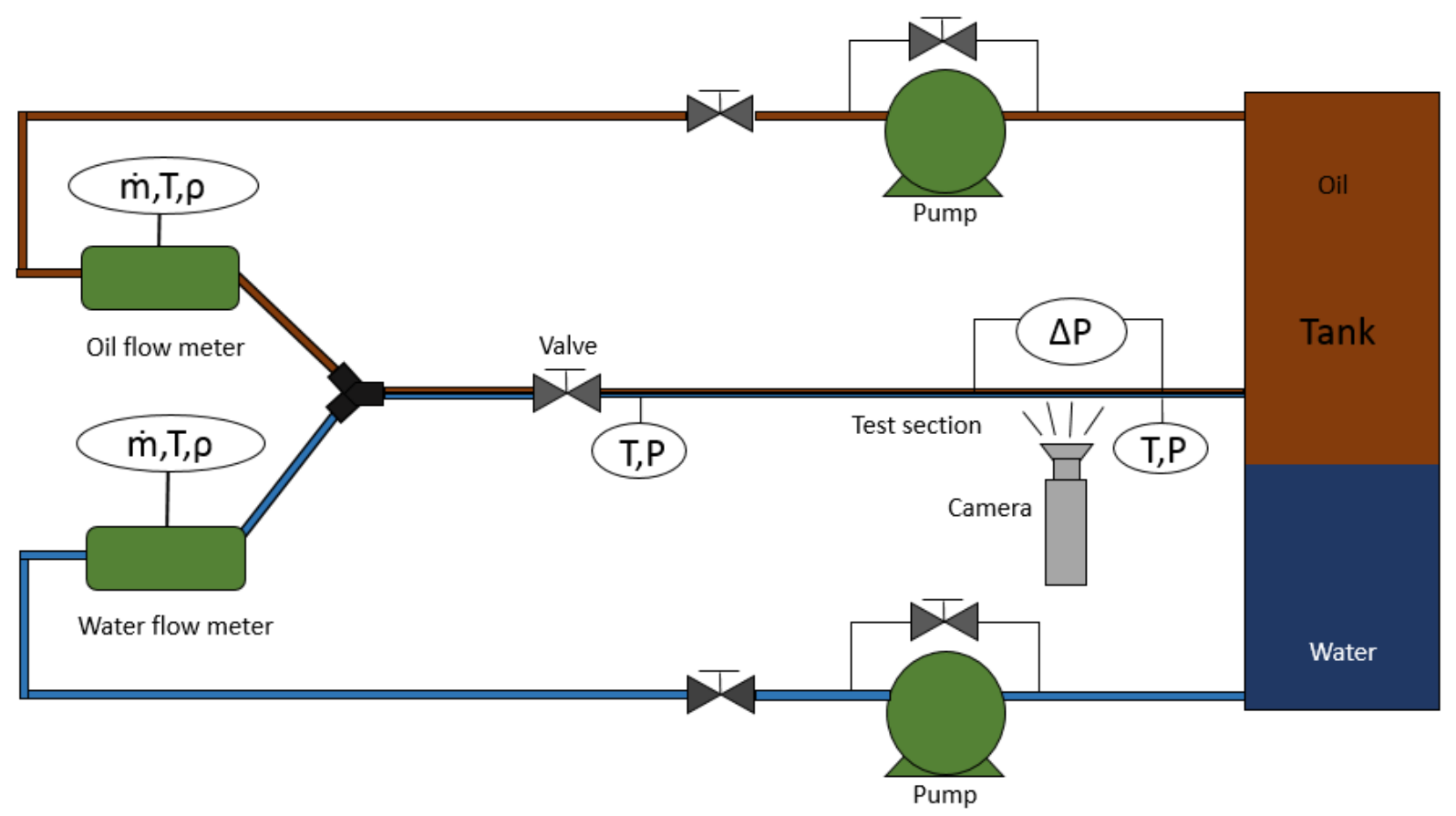

Figure 1 Experimental oil-water closed loop apparatus 


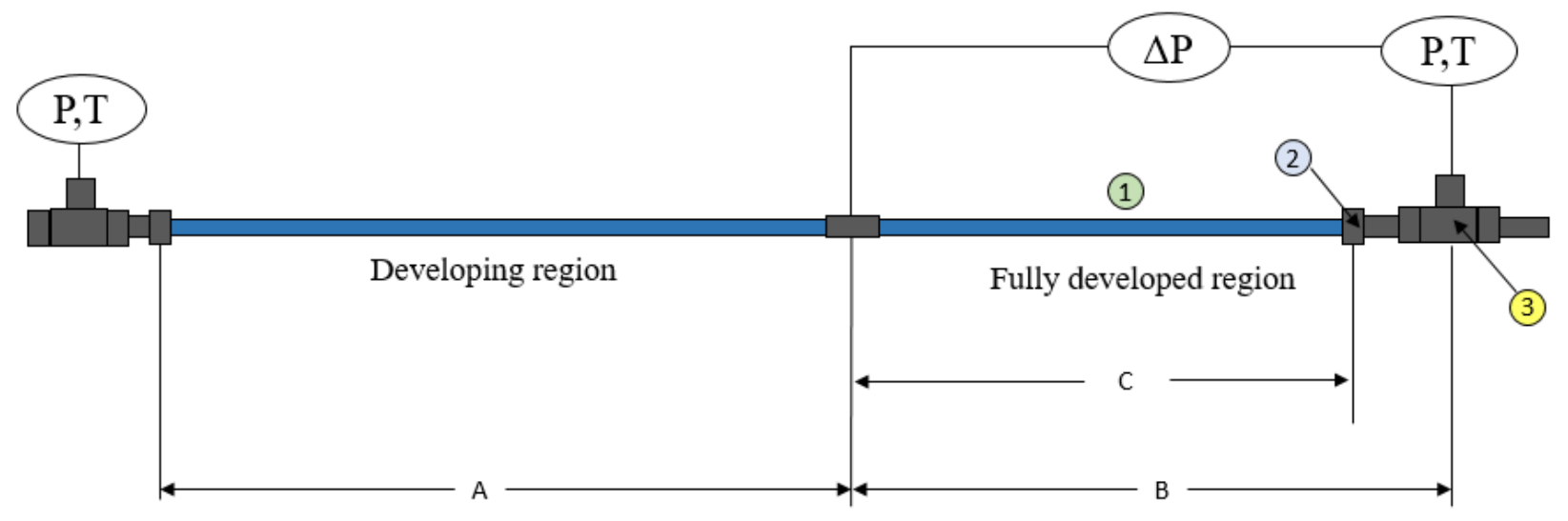

Figure 2 Experimental apparatus test section. A, B, and C represent the lengths of the developing region, fully developed region, and glass section of the fully developed region 

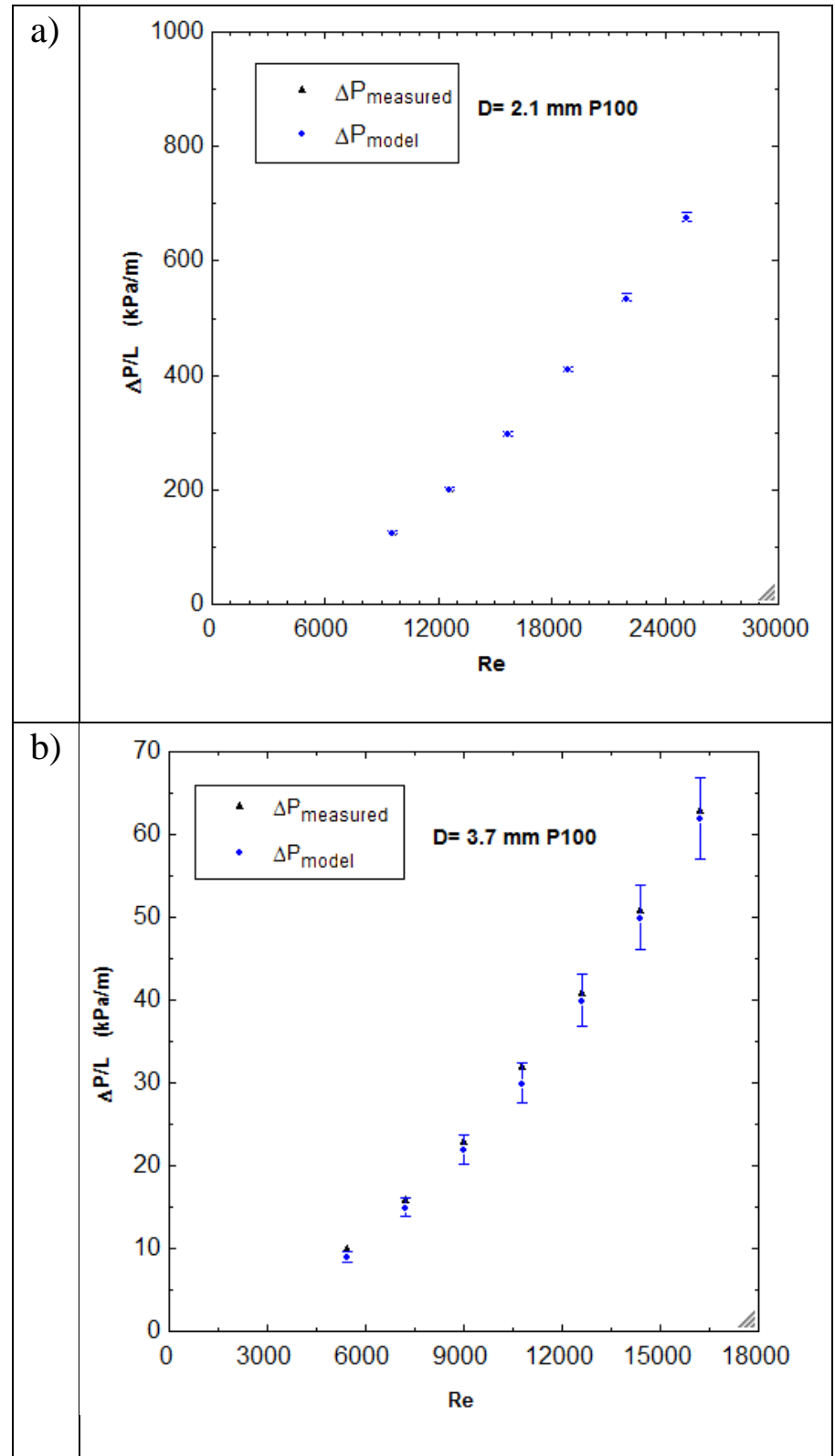

Figure 3 Single-phase water pressured drop for a) $2.1 \mathrm{~mm}$ and b) $3.7 \mathrm{~mm}$ tube 


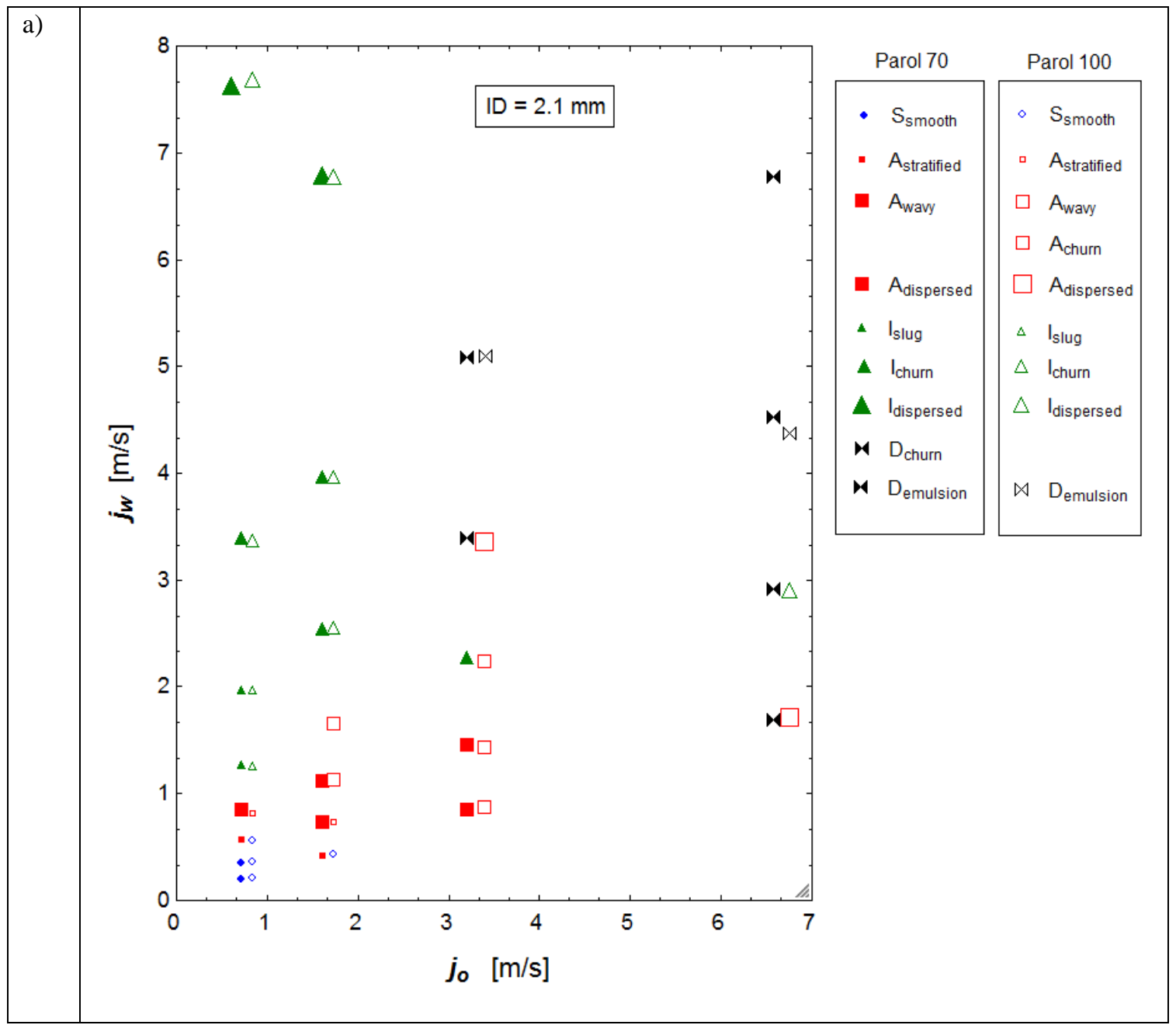




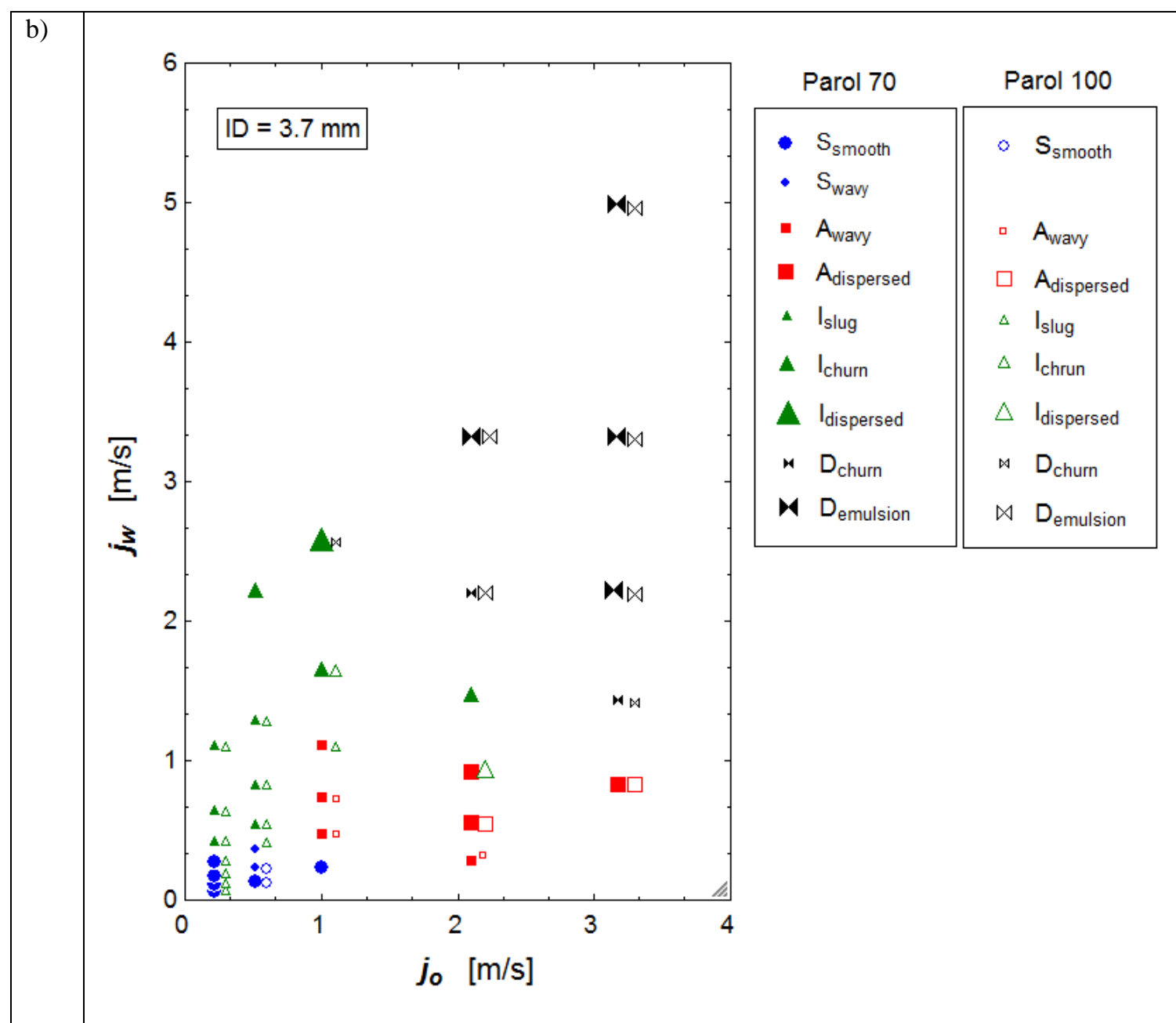

Figure 4 Mini-channel oil and water flow regime maps based on superficial velocity for a) 2.1-mm and b) 3.7-mm for both oils Parol 70 and Parol 100 


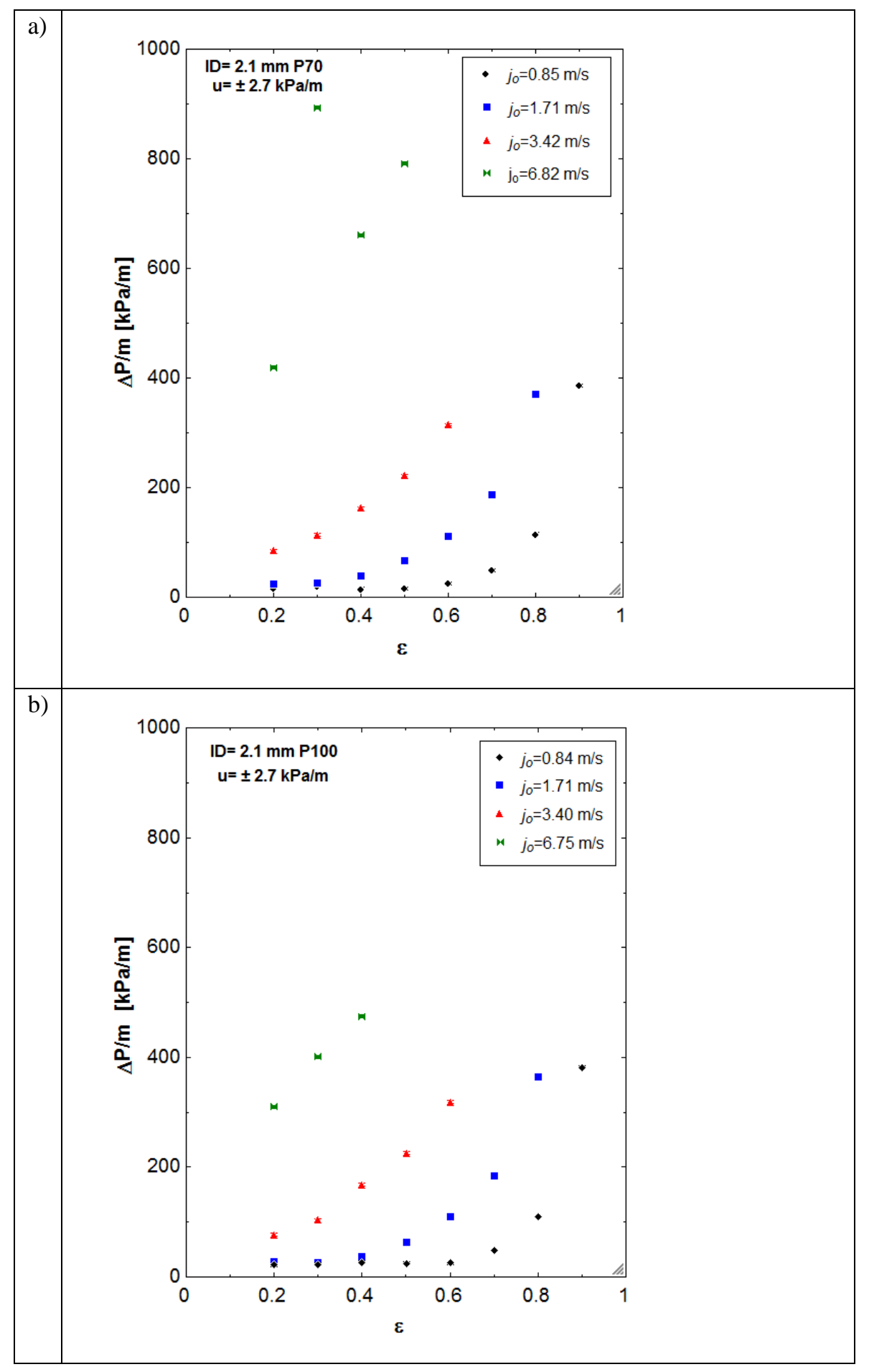




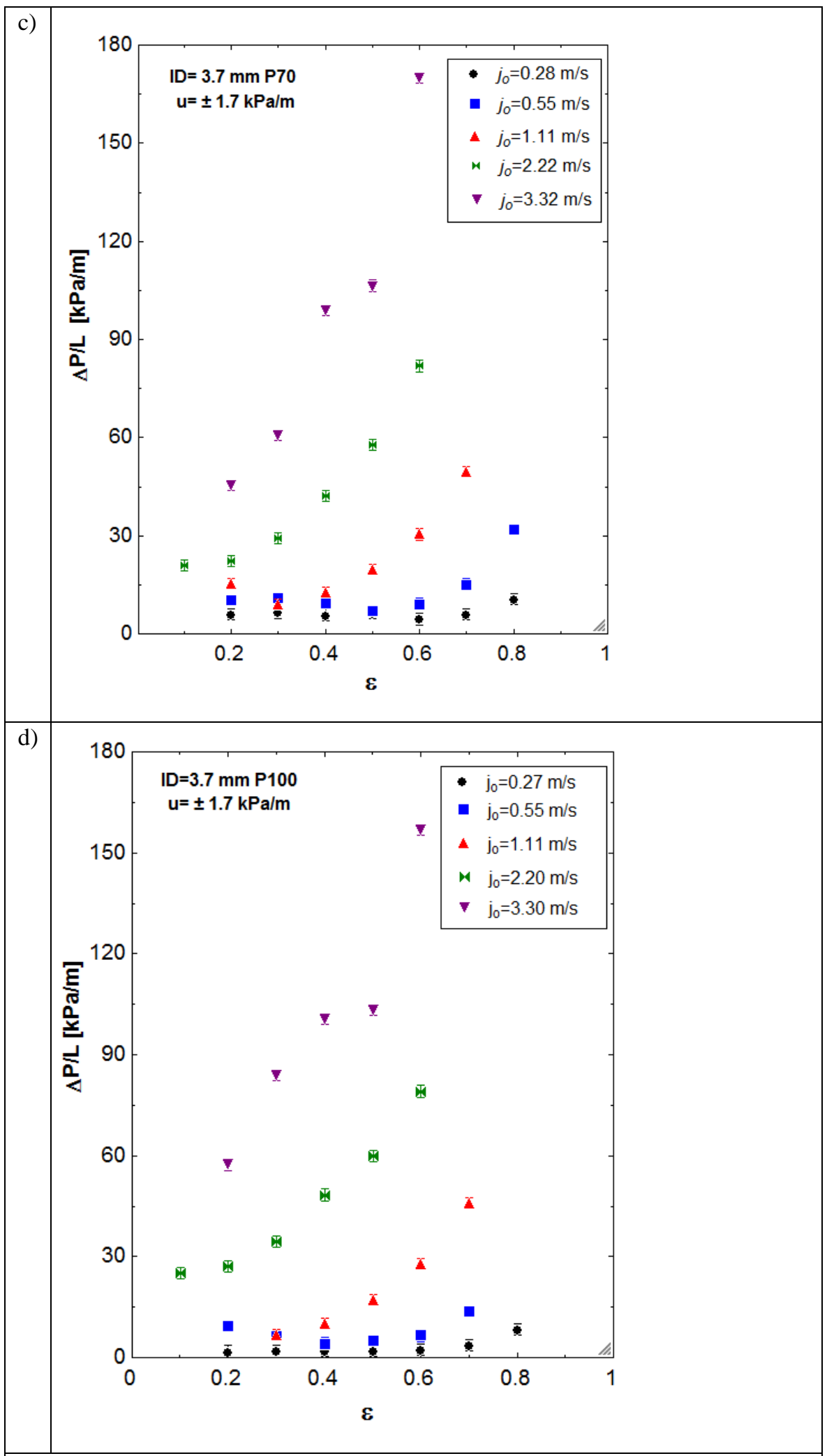

Figure 8 Pressure drop per unit length for a) $D=2.1 \mathrm{~mm}$ and P70, b) $D=2.1$ $\mathrm{mm}$ and P100, c) $D=3.7 \mathrm{~mm}$ and $P 70$, and d) $D=3.7 \mathrm{~mm}$ and $P 100$ 


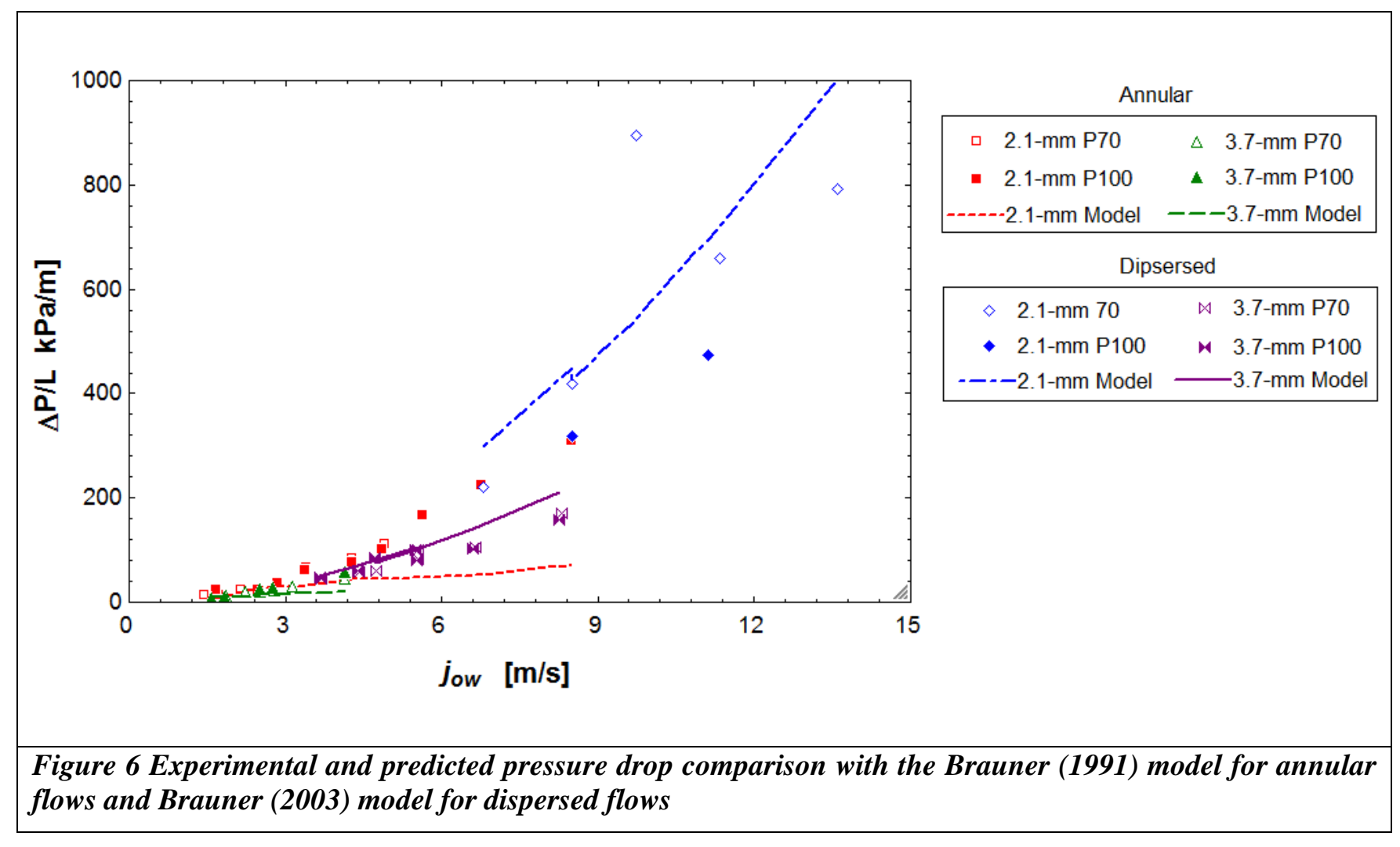




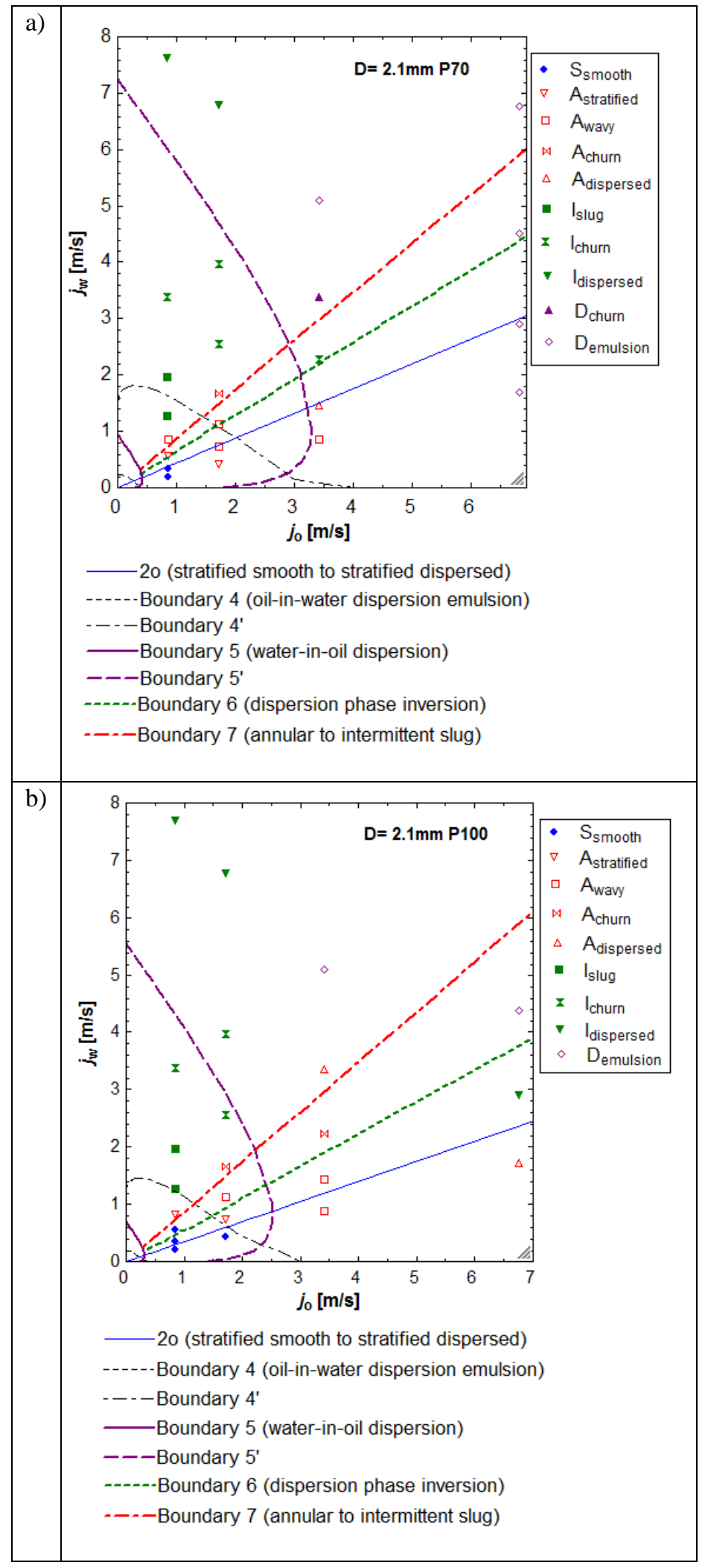




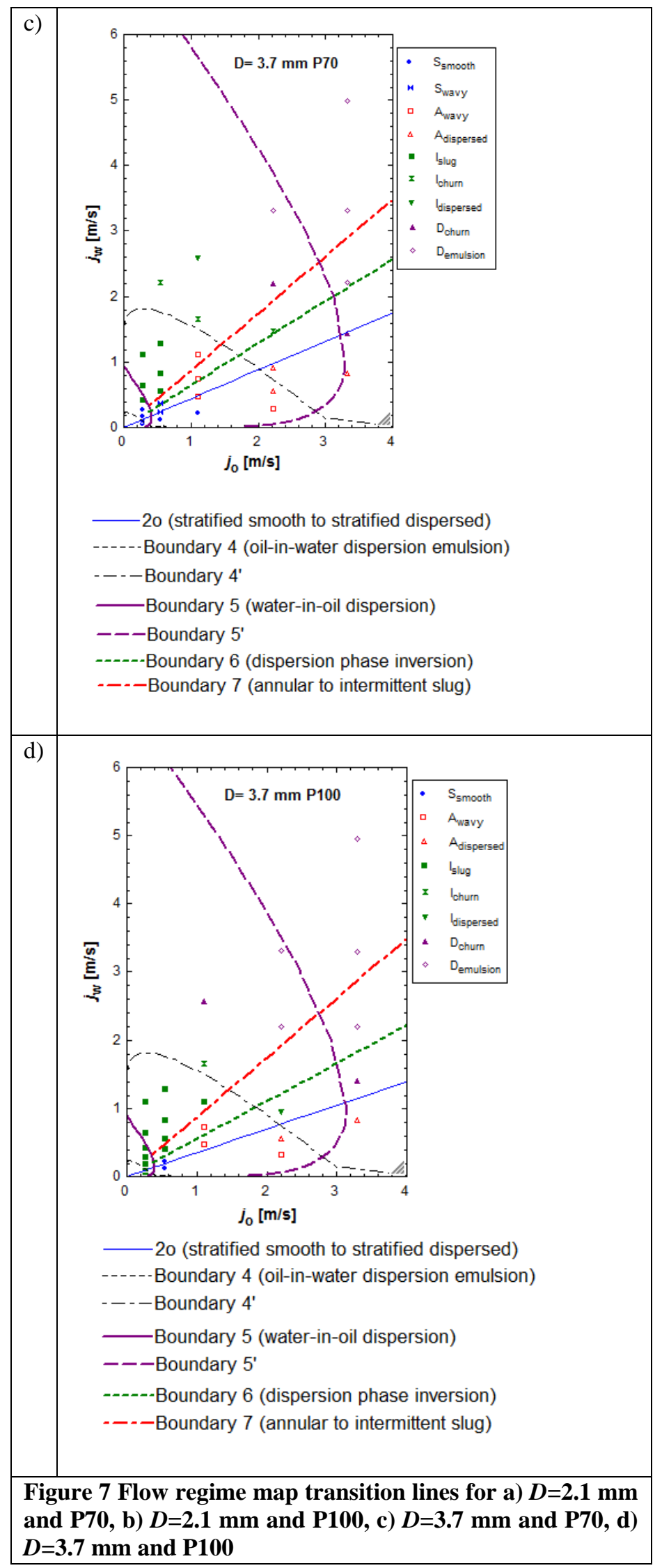




\section{List of Tables:}

Table 1 Tested fluid property range

Table 2 Tube diameter, Eötvös number, and superficial velocity range tested

Table 3 Flow regime map

Table 4: Water phase Reynolds numbers (oil Reynolds numbers were all below $\mathbf{R e}=\mathbf{2 3 0 0}$ )

Table 5 Transition line equations developed by Brauner and Maron (1999) and modified for mini-channels 
Table 1 Tested fluid property range

\begin{tabular}{llcl}
\hline Properties & Water & $\begin{array}{l}\text { Oil } \\
\text { (Parol 70) }\end{array}$ & $\begin{array}{l}\text { Oil } \\
\text { (Parol 100) }\end{array}$ \\
\hline Density at $24^{\circ} \mathrm{C}\left[\mathrm{kg} / \mathrm{m}^{3}\right]$ & $\rho_{w}=997$ & $\rho_{o}=840$ & $\rho_{o}=847$ \\
Viscosity at $23^{\circ} \mathrm{C}, 40^{\circ} \mathrm{C}, 40^{\circ} \mathrm{C}[\mathrm{mPa} \mathrm{s}]$ & $\mu_{w}=1$ & $\mu_{o}=11.7$ & $\mu_{o}=20.8$ \\
Oil-water interfacial tension $[\mathrm{mN} / \mathrm{m}]$ & $30-40$ & & \\
\hline
\end{tabular}


Table 2 Tube diameter, Eötvös number, and superficial velocity range tested

\begin{tabular}{lccc}
\hline Tube ID $(\mathrm{mm})$ & Eo & $j_{\mathrm{o}}(\mathrm{m} / \mathrm{s})$ & $j_{\mathrm{w}}(\mathrm{m} / \mathrm{s})$ \\
\hline 2.1 & 0.2 & $0.84-6.84$ & $0.21-7.69$ \\
3.7 & 0.6 & $0.27-3.30$ & $0.07-4.96$ \\
\hline
\end{tabular}


Table 3 Flow regime map

\begin{tabular}{|c|c|c|c|}
\hline Stratified $(S)$ & Annular (A) & Intermittent (I) & Dispersed $(D)$ \\
\hline 1. $S_{\text {smooth }}$ & 3. Astratified & 7. $I_{\text {slug }}$ & 10. Dannular \\
\hline 2. $S_{\text {wavy }}$ & 4. A wavy & 8. I I & 11. D churn \\
\hline & 5. Achurn & 9. Idispersed & 12. Demulsion \\
\hline & 6. Adispersed & & \\
\hline
\end{tabular}


Table 4: Water phase Reynolds numbers (oil Reynolds numbers were all below $\mathbf{R e}=2300$ )

\begin{tabular}{|l|cc|cc|}
\hline \multirow{2}{*}{ Flow regime } & \multicolumn{2}{|c|}{$R e_{D}$ for $D=2.1-\mathrm{mm}$} & \multicolumn{2}{c|}{$R e_{D}$ for $D=3.7 \mathrm{~mm}$} \\
\cline { 2 - 5 } & Parol 70 & Parol 100 & Parol 70 & Parol 100 \\
\hline Stratified & $444-763$ & $462-1192$ & $255-1370$ & $472-833$ \\
Annular & $881-3531$ & $1564-7068$ & $1034-4092$ & $1725-3047$ \\
Intermittent & $2662-15993$ & $2642-16175$ & $1542-9535$ & $255-6080$ \\
Dispersed & $7114-14185$ & $9183-10725$ & $5253-18400$ & $5216-18283$ \\
\hline
\end{tabular}


Table 5 Transition line equations developed by Brauner and Maron (1999) and modified for mini-channels

\begin{tabular}{|c|c|c|c|}
\hline Boundary & Brauner and Maron (1999) equations & Modified equations for mini-channel flows & \\
\hline 20 & $\begin{array}{l}\tilde{\rho}_{2} u_{2}^{2} \gamma_{2}\left(\gamma_{2}-1\right)+\tilde{\rho}_{1} u_{1}^{2} \gamma_{1}\left(\gamma_{1}-1\right)-\left(\gamma_{2} u_{2}-\gamma_{1} u_{1}\right)^{2}+ \\
\frac{D}{\rho_{12}}\left[\left(\rho_{2}-\rho_{1}\right) g \cos \beta-C_{h} \rho\left(u_{2}-u_{1}\right)^{2} P_{1}\left(\frac{1}{s_{1}}+\frac{1}{S_{2}}\right)\right] \geq 0 \\
\tilde{\rho}_{2}=1+\frac{\rho_{2}}{\rho_{1}} \frac{S_{1}}{S_{2}} ; \tilde{\rho}_{1}=1+\frac{\rho_{1}}{\rho_{2}} \frac{S_{2}}{S_{1}}\end{array}$ & $\begin{array}{l}\tilde{\rho}_{O} u_{o}^{2} \gamma_{o}\left(\gamma_{o}-1\right)+\tilde{\rho}_{W} u_{W}^{2} \gamma_{W}\left(\gamma_{W}-1\right)-\left(\gamma_{o} u_{O}-\gamma_{W} u_{W}\right)^{2}+ \\
\frac{D}{\rho_{O W}}\left[\left(\rho_{O}-\rho_{W}\right) g-C_{h} \rho\left(u_{O}-u_{W}\right)^{2} P_{1}\left(\frac{1}{s_{W}}+\frac{1}{s_{O}}\right)\right] \geq 0 \\
\tilde{\rho}_{o}=1+\frac{\rho_{o}}{\rho_{w}} \frac{s_{W}}{S_{o}} ; \tilde{\rho}_{W}=1+\frac{\rho_{W}}{\rho_{o}} \frac{s_{o}}{S_{W}}\end{array}$ & Eq. (9) \\
\hline 4 & $1.88\left[1+a\left(\frac{j_{o}}{j_{o w}}\right)^{1 / 2}\right]=\left(\frac{0.4 \sigma}{\Delta \rho g D^{2}}\right)^{1 / 2}\left(\frac{\rho_{w D} j_{o w}^{2}}{\sigma}\right)^{0.6}\left(\frac{\nu_{w}}{D j_{o w}}\right)^{0.08}$ & $\begin{array}{l}18.8\left[1+a\left(\frac{j_{o}}{j_{o w}}\right)^{1 / 2}\right]=\left(\frac{0.4 \sigma}{\Delta \rho g D^{2}}\right)^{1 / 2}\left(\frac{\rho_{w D} j_{o w}^{2}}{\sigma}\right)^{0.6}\left(\frac{v_{w}}{D j_{o w}}\right)^{0.08} \\
a=1.43\end{array}$ & Eq. (10) \\
\hline 5 & $1.88\left[1+a\left(\frac{j_{o}}{j_{o w}}\right)^{1 / 2}\right]=\left(\frac{0.4 \sigma}{\Delta \rho D^{2}}\right)^{1 / 2}\left(\frac{\rho_{w D} j_{o w}^{2}}{\sigma}\right)^{0.6}\left(\frac{v_{w}}{D j_{o w}}\right)^{0.08}$ & $\begin{array}{l}18.8\left[1+a\left(\frac{j_{o}}{j_{o w}}\right)^{1 / 2}\right]=\left(\frac{0.4 \sigma}{\Delta \rho D^{2}}\right)^{1 / 2}\left(\frac{\rho_{w D} j_{o w}^{2}}{\sigma}\right)^{0.6}\left(\frac{v_{w}}{D j_{o w}}\right)^{0.08}, \\
a=5.72\end{array}$ & Eq. (11) \\
\hline 6 & $\begin{array}{l}\frac{j_{o}}{j_{o w}}=0.5-0.1088 \log _{10}\left(\frac{\mu_{o}}{\mu_{r}}\right) \\
\mu_{r}=1 \mathrm{mPa} \cdot \mathrm{s}\end{array}$ & & Eq. (12) \\
\hline 7 & $\frac{j_{o}}{j_{w}}=2.875 \times 10^{-3} \frac{\mu_{w}}{\mu_{o}} R e_{w}^{0.8}+1.15$ & & Eq. (13) \\
\hline
\end{tabular}

(C) 2017. This manuscript version is made available under the CC-BY-NC-ND 4.0 license http://creativecommons.org/licenses/by-nc-nd/4.0/ 